\title{
A Ordem do Cânone: episteme da produção discursiva de fãs de ASolaF sobre GoT
}

\section{The Order of the Canon: Episteme of Discourse Production of ASolaF Fans on GoT}

\author{
THIAGO IANATONI CAMARGO \\ Universidade Federal de Pernambuco \\ ANDRÉ LUIZ MARANHÃO DE SOUZA-LẼ̃O \\ Universidade Federal de Pernambuco \\ BRUNO MELO MOURA \\ Universidade Federal de Pernambuco
}

\section{RESUMO}

A série de televisão Game of Thrones (GoT) se tornou um fenômeno cultural, provocando sua avaliação por fãs da saga literária A Song of Ice and Fire (ASoIaF), na qual é baseada. Assumindo, a partir da teoria foucaultiana, as interações fânicas como práticas discursivas e estas como reveladoras de epistemes, a pesquisa analisa como a produção discursiva de fãs de ASoIaF sobre GoT é epistemicamente fundamentada. O método arqueológico foi aplicado à análise dos comentários produzidos em tais interações ocorridas no principal fórum de fãs de ASoIaF. Os resultados revelam quatro formações discursivas, que vão do reconhecimento à reclamação da adaptação. Elas têm em comum a referência ao cânone literário como balizar de tais avaliações, revelando esta instância como sua base epistêmica. Com base na noção foucaultiana de ordem do discurso, propomos haver uma ordem do cânone que norteia a construção de verdades pelos fãs acerca da transmidiação do universo ficcional.

Palavras-chave: Episteme. Fãs. Arqueologia. Foucault. CCT.

\section{Abstract}

The TV series Game of Thrones (GoT) has become a cultural phenomenon, provoking its evaluation by fans of the literary 
saga A Song of Ice and Fire (ASoIaF), on which it is based. Assuming, based on Foucault's theory, that fan interactions are discursive practices and that these practices reveal epistemes, the research analyzes how the discursive production of ASoIaF fans about GoT is epistemically grounded. The archaeological method was applied to the analysis of the comments produced in such interactions that occurred in the main forum of ASoIaF fans. The results reveal four discursive formations, ranging from recognition to complaint about the adaptation. They have in common the reference to the literary canon as a basis for such evaluations, revealing this instance as its epistemic basis. Based on the Foucauldian notion of order of the discourse, we propose that there is an order of the canon that guides the construction of truths by fans about the transmedia of the fictional universe.

Keywords: Episteme. Fans. Archeology. Foucault. CCT.

\section{INTRODUÇÃO}

Uma das ações da indústria do entretenimento que mais ressoou nos últimos anos foi o anúncio da adaptação televisiva, produzida pelos canais $\mathrm{HBO}$, da saga literária de fantasia aclamada nos EUA: A Song of Ice and Fire (ASoIaF) (SARIKAKIS; KRUG; RODRIGUEZ-AMAT, 2017; YOUNG, 2014). Lançada em 1996 pelo escritor George R. R. Martin (GRRM), um ex-roteirista de Hollywood, a saga ganhou notoriedade por misturar em seu enredo aspectos e criaturas fantásticas, batalhas medievais e, principalmente, tramas políticas. Durante anos, produtores de cinema tentaram um acordo com o autor para levar a trama para uma outra mídia, mas não conseguiram sucesso. Foi a partir de 2011, intitulada como Game of Thrones (GoT) e sob a liderança de David Benioff \& D. B. Weiss (D\&D) como produtores, que a saga foi produzida como uma série televisiva que, em pouco tempo, se tornou uma das mais aclamadas do segmento (LOWDER, 2012).

O programa para TV se provou um estrondoso fenômeno econômico e cultural. Seus números estabeleceram novos recordes ao segmento televisivo: conteúdo mais assistido na TV por assinatura (CLARK, 2019), maior número de expectadores simultâneos por um episódio (BURTON, 2019), número de prêmios (i.e., Emmy) conquistados por um mesmo show (MAAS, 2019) e série mais pirateada da 
história (MACNEILS, 2017). Durante nove anos, a exibição de GoT alcançou uma grande comoção não apenas entre sua audiência, mas também entre os fãs de ASoIaF (ELLIS, 2019; SARIKAKIS; KRUG; RODRIGUEZ-AMAT, 2017).

Enquanto fãs, não lhes basta apenas um consumo receptivo de um produto massivamente distribuído pela indústria do entretenimento, é preciso participar ativamente de atividades que revelam essa posição fânica (DE SOUZA-LEÃO et al., 2019; HACKLEY; HACKLEY, 2018). Tais atividades são propiciadas, simultaneamente, pela disponibilidade de novas tecnologias que ampliam as possibilidades de relações fânicas e pela convergência entre espaços socioculturais (e.g., digitais, físicos) em que interagem com seus pares (GUSCHWAN, 2012; JENKINS, 2015).

As trocas entre fãs extrapolam o conceito de consumo e produto, quando eles acabam tomando para si funções que, notadamente, pertencem aos produtores (e.g., espalhar conteúdo) (DE SOUZA-LEÃO; COSTA, 2018; JENKINS; FORD; GREEN, 2013). Neste sentido, atuam como prossumidores que, no contexto da Web 2.0, são fonte de repetição, reformulação e enunciação de discursos mercadológicos alinhados ou não ao interesse de outros agentes de mercado (BEIGHTON, 2016; CHEN, 2018).

Discursos mediados através do mercado possibilitam o entendimento de como diferentes verdades são incorporadas pelos consumidores (BOKEK-COHEN, 2016; FYRBERG YNGFALK et al., 2013; GODFREY; LILLEY, 2009). Assim, auxiliam a entender como a cultura do consumo pode ser entendida como uma rede distribuída (ARNOULD; THOMPSON, 2015), em que diferentes discursos mercadológicos são incorporados, negociados e propagados através de uma relação mútua entre práticas culturais e consumeristas (DUJARIER, 2014).

Para Foucault (2009), o discurso é uma prática transversal e dinâmica, produzido numa gama de procedimentos que são capazes de redistribuir significados e posicionar os sujeitos. É um conjunto heterogêneo que combina saberes a partir de um acontecimento, até que se alcance certa regularidade. Essa regularidade está na forma como os saberes são inscritos em determinadas relações sociais (i.e., de poder, ética) num movimento que os liberta de sujeições 
históricas. Ao constituir um discurso, os saberes podem produzir, acumular e circular o funcionamento de conhecimentos que Foucault (2009) denomina como episteme. Quando diferentes discursos são combinados, negociados e ressignificados, extrapolam a concepção da linguagem, ressoando práticas sociais que podem ser estratificadas nos saberes que compõem as epistemes (FOUCAULT, 2012a).

Com base nisso, a presente pesquisa observa os movimentos discursivos dos fãs do universo ficcional criado por GRRM a partir do consumo de sua adaptação televisiva. Para isso, propomos a seguinte questão investigativa: Como a produção discursiva de fãs de ASoIaF sobre GoT é epistemicamente fundamentada?

O presente estudo considera que as contribuições teóricas e metodológicas de Michel Foucault podem contribuir para o entendimento de práticas de mercado que concebem o consumo como fenômeno cultural (ARNOULD; THOMPSON,2015). Ao assumir a cultura como uma rede distribuída, apresentamos uma investigação alinhada ao eixo temático do campo que indica como redes mediadas pelo mercado incorporam o consumo, de modo que saberes mercadológicos conduzem o comportamento de consumidores (DENEGRI-KNOTT; NIXON; ABRAHAM, 2018; DUFFY, 2014; SREDL, 2018) e modificam as experiências de consumo (KARABABA; GER, 2011; VOASE, 2007). Como escopo, nos debruçamos sob arranjos sociais de fãs que permitem compreender como os saberes de mercado fazem ressoam sobre práticas consumeristas especializadas (i.e., fânicas) (PARMENTIER; FISCHER, 2015; ZAJC, 2015) a partir do entendimento que a indústria do entretenimento é um segmento econômico de ressonância cultural, na qual, a medida em que comercializam diferentes produtos amparados em estratégias de marketing massivamente mediada, repercutem sobre a cultura pop, oferecendo recursos que atendem as necessidades sociais dos consumidores (HACKLEY; HACKLEY, 2018; NAVARRO, 2015).

\section{Produção discursiva CoMo REVELAdora de EPISTEMES NA FILOSOFIA FOUCAULTIANA}

A forma como os indivíduos incorporam para si, ressignificam e propagam compreensões sociais é denominada por Foucault (2016) como vontade de saber. Ao negociar concepções e conhecimentos 
que fazem parte de si, mas não são limitados a si, lhes é permitido negociar aquilo que se enuncia. É nisso que se configura o corte entre episteme, doxa (i.e., opinião) e techné (i.e., arte). Episteme é uma forma de compreensão que permite observar formas de subjetivação e entendimentos a respeito de como os indivíduos concebem e usufruem suas experiências por meio da sua relação com diferentes saberes que têm contato durante sua existência (FOUCAULT, 2009; 2016).

Para Foucault (2016), a episteme é um espaço que se situa historicamente na repartição e repetição de enunciações distintas, aludindo aos campos de saberes que constituem conhecimentos sobre um dado objeto ou fenômeno. Em seu entendimento, Foucault (2009) apresenta o saber como construção história que produz verdades instaladas e reveladas no modo como os sujeitos enunciam sobre um objeto ou fenômeno. Identificar como acontecem as enunciações permite, então, ultrapassar os limites do saber e observar como se estabelecem as verdades.

A noção de verdade orienta e legitima as práticas sociais. Ela resulta de um jogo de relações discursivas que, sob certas circunstancialidades históricas e localizadas, estabelece o estatuto do verdadeiro (FOUCAULT, 2016). Desta forma, verdades são intrínsecas ao conhecimento e a questões históricas, funcionando como produções sociais sistemáticas que posicionam saberes ora como verdadeiros, ora como um entendimento ainda a ser verificado (FOUCAULT, $2012 b$ ). Aquilo que se pode dizer como verdade ocorre de forma imanente, por meio das condições e procedimentos que possibilitam que certos saberes se sustentem ante outros (FOUCAULT, 2016). Assim, quando um discurso se sobrepõe a outro, estabelece uma negociação de verdades que Foucault (2012) denominou de jogos de verdade, um processo por meio do qual verdades construídas e legitimadas.

Esse processo faz a episteme funcionar como uma conjunção de elementos que permite entender como os sujeitos podem ser pensados e conduzidos. Logo, ao estabelecer possibilidades de formas de conduta, os saberes fundamentam relações de poder. Esta condução se caracteriza pela sua historicidade; saberes sustentados por diferentes campos de saberes e posições de fala acerca de certos objetos são simultaneamente constituídos por suas verdades e in- 
fluenciados por condições que lhes são externas. Com isto, carregam certas semelhanças e diferenças (FOUCAULT, 2009).

O saber é um campo em que diferentes signos são associados, de modo que aludem a certas materialidades (e.g., históricas, contextuais) que se aplicam e se transformam por meio de discursos (FOUCAULT, 2016). Por consequência, Foucault (2009) considera que a compreensão de como os saberes surgem e se transformam a partir de estruturas sociais, institucionais e políticas emanam dos discursos que lhe sustentam. Eles são transversais documentos, signos particulares, elementos identificáveis na fala, condições de contextualização e práticas sociais.

Os discursos são, em última instância, uma prática constituída por saberes que revelam aspectos (i.e., o que, como, por que, por quem, quando se diz) que tanto permite lhes identificar quanto os torna possíveis. Como tal, une a linguagem a outras práticas (i.e., não-discursivas) sociais (i.e., o que, como, por que, por quem, quando se faz). Assim, as práticas discursivas são o elo entre o que se sabe e o que exerce, revelando realidades materiais (FOUCAULT, 2009).

\section{DiscuRsos MERCADOLógicos}

O mercado pode ser entendido como um espaço social de relações baseadas em poder e produção de saberes (CANNIFORD; KARABABA, 2013; GALVAGNO, 2011). Assim, certas práticas (e.g., consumo) estabelecem condições que possibilitam a constituição de discursos que conduzem as lógicas sociais de mercado (CANNIFORD; KARABABA, 2013; BRYCE; MACLAREN; O'GORMAN, 2012).

Neste sentido, uma das práticas da gestão de marketing é a produção de discursos que tentam angariar a aproximação e preferência dos consumidores (FOUGÈRE; SKÅLÉN, 2012). O discurso de marketing visa à promoção de um sistema de mercado no qual os consumidores são idealizados como sujeitos com competências específicas que os capacita a consumir. Embora esse discurso atribua ao consumidor uma maior responsabilidade, tende a diminuir sua liberdade ao atribuir-lhe deveres e responsabilidades para exercer suas escolhas de consumo (COVA; COVA, 2012; GIESLER; VERESIU, 2014). Ele é apontado como sendo responsável pela individualização dos consumidores, por meio da gestão de suas neces- 
sidades (GURRIERI; BRACE-GOVAN; PREVITE, 2014; YNGFALK; FYRBERG YNGGALK, 2015), podendo transformar cidadãos ativos em consumidores passivos e a incorporação comunitária em individualismo competitivo (GALVAGNO, 2011). Dessa forma, reflete a estratégia de orientar o comportamento do consumidor na sociedade (FOUGÈRE; SKÅLÉN, 2012), estimulando pessoas a recorrerem ao mercado para maximizar sua qualidade de vida (DU GAY, 1996) e fazer uso de bens e serviços específicos para alcançar certo status social (THOMPSON, 2004).

Tal corrente de pensamento propiciou um rápido crescimento de ideias e práticas organizacionais centradas no papel do consumidor (FOUGËRE; SKÅLÉN, 2012) como a lógica dominante do serviço (VARGO; LUSH, 2004), a lógica dominante do cliente (HEINONEN et al., 2010), o valor da experiência do consumo (HELKKULA; KELLEHER; PIHLSTROËN, 2012). Seu discurso subjacente compreende que as capacidades humanas (e.g., conhecimentos, habilidades) são ativos imateriais (CAMPBELL; O'DRISCOLL; SAREN, 2013; JOHNSON; THOMAS; GRIER, 2017). Até mesmo o discurso do marketing social concebe perspectivas de governança neoliberal que, sob a ideia de uma comercialização racional, apontam como o bem-estar do consumidor está em se alinhar, espontaneamente, aos interesses de outros agentes mercadológicos (YNGFALK, 2015).

A agência do consumidor passou a ser considerada como uma fonte potencial de competência mercadológica (FYRBERG YNGGALK, 2013; YNGFALK; FYRBERG YNGGALK, 2015), o que foi legitimado pela concepção de autorrealização por meio de consumo (WELCH, 2020; YNGFALK; FYRBERG YNGGALK, 2015). Contudo, discursos de mercado não são apenas aqueles que objetivam serem apreendidos pelos consumidores (BEIGHTON, 2016). Os consumidores são capazes de ressignificar valores dos objetos consumidos com o intuito de atender suas próprias demandas, buscando autonomia em suas práticas consumeristas (GALVAGNO, 2011; KOZINETS; HANDELMAN, 2004). Arnould (2007) indica que as novas formas de consumir fundam uma transição no status do consumidor: de agentes de mercado caracterizados pela recepção passiva a indivíduos que se manifestam sobre o que consomem de formas ativas (e.g., proativa, criativa). 
A proatividade e a criatividade dos consumidores lhes permite escolher seu próprio destino de consumo, quando fazem uso dessas escolhas para dialogar e manifestar identidades, alçando a prática como uma expressão de si (BEIGHTON, 2016; COVA; COVA, 2012). O mercado, então, pode ser compreendido como uma arena política, em que práticas de consumo podem funcionar como uma luta de caráter simbólico para evitar regulações de marketing (GALVAGNO, 2011; KOZINETS; HANDELMAN, 2004).

\section{INTERAÇõES FÂNICAS COMO PRÁTICAS DISCURSIVAS}

No campo da cultura pop a lógica de mercado também estabelece uma disputa simbólica entre diferentes agentes. Por um lado, a indústria do entretenimento se apropria de uma gama de objetos culturais midiáticos e os ressignifica para o mercado, transformando-os em estilos de vida padronizados mediante a entrega em ampla escala de produtos que manifestam estes signos (BOOTH, 2018). Por outro, os fãs, principais consumidores do segmento, produzem sua própria perspectiva sobre o que consomem. Eles endossam o entendimento de que o consumo é uma prática que produz discursos que extrapolam o âmbito mercadológico através de seu engajamento típico com os objetos midiáticos (CHEN, 2018; DE SOUZA-LEÃO; MOURA, 2018)

O engajamento dos fãs indica que sejam consumidores produtivos (CHEN, 2018; DE SOUZA-LEÃO; COSTA, 2018) por se considerarem responsáveis por, entre outras funções, espalhar o conteúdo que consomem por meio, principalmente, de suas interações virtuais (JENKINS; FORD; GREEN, 2013). Esse processo ocorre em meio a um contexto de cultura participativa (DE SOUZA-LEÃO; COSTA, 2018; SUGIHARTATI, 2020), definida por Jenkins (2006; 2008) como um contexto em que diferentes indivíduos convergem por meio de uma apropriação da tecnologia disponível, estabelecendo relações virtuais com pares com gostos e prerrogativas similares, desenvolvendo um senso de comunidade.

Os fãs se revelam um exemplo crasso dessa cultura, pela maneira com que se tornam parte ativa e produtiva do mercado em virtude da relação íntima que nutrem com o produto de mídia consumido. Seu consumo se caracteriza como um consumo de práticas 
(GUSCHWAN, 2012; FUSCHILLO, 2016), por meio de uma participação ativa na busca de novas experiências (JENKINS, 2015). Essas práticas evidenciam intenso interesse pelo consumo e produção de conhecimento como meio de socialização, assim como revelam grande afeição e entusiasmo em relação aos produtos de mídia aos quais estão vinculadas (SEREGINA; SCHOUTEN, 2017; ZAJC, 2015).

As práticas fânicas são performances capazes de intensificar ou mitigar concepções sociais e culturais (i.e., gênero, raça, nacionalidade, geração), quando, ao (re)consumir o texto midiático, (re) combinam conteúdos produzidos para finalidades mercadológicas em atividades que expressem percepções particulares (CERVELLON; BROWN, 2018; SEREGINA; WEIJO 2016). Essa assimilação e (re) produção do texto para outras finalidades não tem o propósito de rivalizar ou antagonizar o produto original, mas possibilitar interações sociais por meio da circulação de artefatos, memórias e compartilhamento de sentimentos (GRAY, 2010).

Esse processo ocorre sobremaneira em espaços sociais denominados fandoms (GUSCHWAN, 2012; SEREGINA; WEIJO, 2016), onde os fãs se sentem confortáveis e estimulados à propagação de conhecimento e ao compartilhamento de experiências acerca dos produtos de mídia (GUSCHWAN, 2012; FUSCHILLO, 2016). Nesses espaços eles se sentem à vontade para assumir narrativas, signos e valores apropriados desses objetos, ressignificando-os (JENKINS, 2015). Assim, é em meio à comunidade que os fãs estabelecem suas práticas, que tanto podem ser novas produções (e.g., fanfictions) como discussões que expressam suas impressões sobre os produtos de mídia (e.g., fan theories) (DE SOUZA-LEÃO et al., 2019; FUSCHILLO, 2016). Tais discussões se configuram como práticas verbais que expandem o conteúdo do texto midiático (CHEN, 2018; DE SOUZA-LEÃO; COSTA, 2018), podendo ser compreendidas como práticas discursivas.

\section{Procedimentos metodológicos}

A pesquisa está em consonância à emergência epistemológica em desenvolvimento à CCT (ARNOULD; THOMPSON, 2015), se alinhando a uma perspectiva pós-estruturalista (MORDUE; DENNIS, 2017). O estudo foi realizado com abordagem semi-indutiva, 
assumindo concepções a priori como forma de subsidiar a proposta do estudo, mas retornando à teoria para interpretar os achados (LEÃO; MELLO; VIEIRA, 2011).

Em consonância com essas escolhas, adotamos o método arqueológico proposto por Michel Foucault, que evidencia as condições de existência que sustentam a produção de certos discursos. O mesmo se dá por meio de uma análise de discurso fundamentada na identificação de enunciados que compreendem um conjunto de relações que fornecem as condições para a significação de um dado saber (FOUCAULT, 2009). Trata-se de um processo que objetiva apresentar as condições históricas que formulam concepções epistêmicas por meio de práticas discursivas (DELEUZE, 2005; THIRY-CHERQUES, 2010).

Como ponto de partida, a arqueologia deve identificar um acontecimento discursivo que embase o problema investigado. A partir disto, é possível se formular um arquivo de dados capaz de revelar as práticas discursivas a serem analisadas. $\mathrm{O}$ método deve, nesse processo, revelar regularidades discursivas presentes nesse arquivo (FOUCAULT, 2009)

Para a execução da pesquisa, seguimos as instruções apresentadas por de Souza-Leão (DE SOUZA-LEÃO; COSTA, 2018; DE SOUZA-LEÃO; MOURA, 2018), que sistematizou etapas e procedimentos para a operacionalização da Análise de Discurso Foucaultiana (ADF) conforme os fundamentos apresentados pelo filósofo. Assim, a proposta detalha o caminho analítico pelo qual enunciados convergem em formações discursivas. Tais enunciados são caracterizados por funções enunciativas, enquanto as formações discursivas são embasadas em regras de formação. Funções enunciativas e regras de formação são constituídas por certos critérios que, por serem análogos, permitem que as relações entre esses níveis sejam identificadas. Tais categorias compõem a ADF. O Quadro 1 as descreve, bem como aos critérios das funções enunciativas e das regras de formação. 


\title{
Quadro 1 - Descrição das categorias analíticas
}

\begin{abstract}
Enunciado
São funções de existência que cruzam a estrutura da linguagem e os domínios de saberes, revelando temas contingentes a um tempo e lugar. São as unidades básicas do discurso, e sua existência ocorre em textos, contextos e relações com outros enunciados.
\end{abstract}

\section{Função enunciativa}

Refere-se ao nível performático dos enunciados, indicando as finalidades dos discursos. São evidenciadas por meio de quatro critérios complementares:

\begin{tabular}{|l|l|l|l|}
\hline Referencial & Sujeito & Campo associado & $\begin{array}{l}\text { Materiali- } \\
\text { dade }\end{array}$ \\
\hline $\begin{array}{l}\text { Diz respeito ao que o } \\
\text { enunciado trata, confe- } \\
\text { rindo caráter de existên- } \\
\text { cia ao que os discursos } \\
\text { se referem. }\end{array}$ & $\begin{array}{l}\text { Refere-se a posições de } \\
\text { fala por meio das quais } \\
\text { os enunciados são } \\
\text { proferidos. }\end{array}$ & $\begin{array}{l}\text { Condiz aos domínios de sa- } \\
\text { beres que fundamentam e } \\
\text { possibilitam a concepção e } \\
\text { a produção de enunciados. }\end{array}$ & \begin{tabular}{l}
$\begin{array}{l}\text { enunciado se } \\
\text { revela, possi- } \\
\text { bilitando sua } \\
\text { concretização } \\
\text { e repetição. }\end{array}$ \\
\hline Regras de formação
\end{tabular} \\
\hline
\end{tabular}

Trata-se de fundamentos que estabelecem (co)existência, manutenção, modificação e desaparecimento de saberes, provendo condições de possibilidade para as formações discursivas. Também são evidenciadas por meio de quatro critérios:

\begin{tabular}{|l|l|l|l|}
\hline Objeto & Modalidade & Conceito & Estratégia \\
\hline $\begin{array}{l}\text { Dão forma aos enuncia- } \\
\text { dos, sendo demarcados } \\
\text { pelos lugares, limites e } \\
\text { especificações dos seus } \\
\text { referenciais. }\end{array}$ & $\begin{array}{l}\text { Revela o modo como } \\
\text { os sujeitos articulam e } \\
\text { expressam enunciados. }\end{array}$ & $\begin{array}{l}\text { Concepções presentes nos } \\
\text { enunciados a partir de cer- } \\
\text { tos campos de saberes. } \\
\text { forma ado- } \\
\text { tada para } \\
\text { se alcançar } \\
\text { o propósito } \\
\text { do discurso } \\
\text { a partir da } \\
\text { maneira } \\
\text { como este se } \\
\text { materializa. }\end{array}$ \\
\hline $\begin{array}{l}\text { Formações discursivas } \\
\text { Refere-se a certa regularidade com que os discursos se constituem, permitindo se evidenciar } \\
\text { funterligados a partir de suas funções enunciativas, sob certas regras de formação. }\end{array}$ \\
\hline
\end{tabular}

Fonte: adaptado da sistematização proposta por de Souza-Leão e Moura (2018) a partir de Foucault (2009).

\section{Dentro de sua lógica de convergência, o procedimento revela feixes de relações entre essas categorias. O processo tem início na}


identificação dos enunciados. Daí, eles são escrutinados em relação aos critérios de suas funções enunciativas. As relações sintagmáticas entre tais critérios permite a identificação das funções presentes no arquivo, podendo acontecer de um enunciado revelar mais de uma função, assim como uma mesma função dizer respeito a mais de um enunciado. Além disto, os enunciados podem ter relações entre si, também mapeáveis pelos critérios identificados, o que revela a tendência de feixes de relações relativas às suas funções. Essas relações podem ser de dois tipos: síncronas, quando enunciados evidenciam condições de coexistência no arquivo; e incidentes, quando o arquivo revela que a existência de certos enunciados pressupõe a de outros. na forma como alguns enunciados ampliam a concepção de outro. Os critérios de funções enunciativas também são a base para a identificação dos critérios de regras de formação, que lhe são homólogos. Assim, certos referenciais correspondem a determinados objetos; os sujeitos se posicionam em certas modalidades; campos associados fundamentam certos conceitos; e materialidades revelam estratégias. Novamente não se trata de relações lineares, todavia, geram convergências. São essas convergências que permitem que a regras de formação indiquem os padrões de feixes que fundamentam as formações discursivas. Essa mesma lógica, com base nos feixes que sustentam as formações discursivas, permite se inferir a(s) episteme(s) reveladas em um arquivo. A Fig. 1 ilustra esse processo.

\section{Figura 1 - Processo analítico}

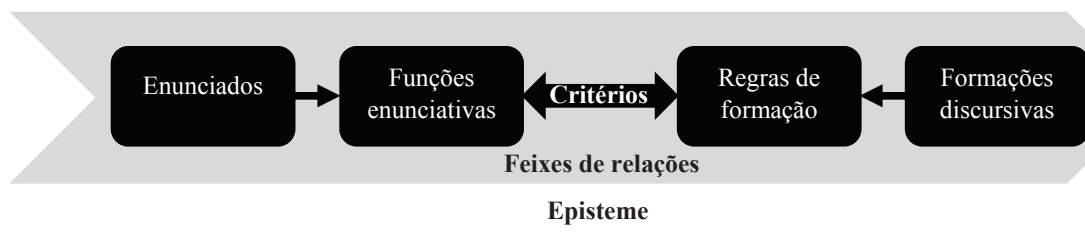

Fonte: adaptado da sistematização proposta por de Souza-Leão e Moura (2018) a partir de Foucault (2009).

Para a formação do arquivo de pesquisa, acessamos o portal Westeros.org, principal fórum de fãs de ASoIaF. Proposto, ini- 
cialmente, como uma enciclopédia virtual (i.e., Wiki) de fãs para fãs, posteriormente passou a ser considerado uma fonte de informações canônicas sobre a saga, uma vez que seus criadores (i.e., moderadores-chefe), Elio Garcia e Linda Antonson, apresentaram um trabalho tão rico e fidedigno ao conteúdo dos livros que foram as únicas pessoas convidadas pelo próprio GRRM para expandir e complementar seu universo ficcional (GARCIA; ANTONSON; MARTIN, 2014; SARIKAKIS; KRUG; RODRIGUEZ-AMAT, 2017).

Além de informações sobre a saga, o portal dispõe de um fórum em que fãs do produto cultural podem discutir sobre quaisquer assuntos (YOUNG, 2014). Os principais tópicos discutidos são aqueles que tratam dos conteúdos presentes em distintas mídias da saga (e.g., televisiva e literária). Logo, nos debruçamos sobre os comentários que discutem cada episódio da série. Para tanto, analisamos um total de 19.960 mensagens, postadas nos 73 tópicos equivalentes a todos os episódios das oito temporadas do programa televisivo, exibidos entre 2011 e 2019.

\section{APRESENTAÇÃo E REFLEX̃̃o dos RESULTADOS}

Nossa análise identificou um conjunto de enunciados que culminam em quatro formações discursivas e uma única episteme (vide Fig. 2). Seguindo a lógica apresentada, subdividimos a presente seção em três partes: na primeira, apresentamos os enunciados a partir de suas funções, ilustrados em contextualizações das situações empíricas observadas no arquivo; na segunda, as formações discursivas são apresentadas a partir de suas regras de formação, com exemplos retirados do arquivo de pesquisa que ilustram os feixes completos que lhes dão sustentação; por fim, discutimos a episteme identificada a partir de uma retoma da teoria.

\section{Enunciados e suas Funções Enunciativas}

A primeira função enunciativa evidencia o potencial de GoT (FE1), ao destacar seu alcance mercadológico e cultural. Isso é decorrente de como práticas discursivas aludem à projeção de GoT (referencial) na perspectiva da indústria do entretenimento (campo associado), revelando o envolvimento (sujeito) dos fãs de ASoIaF 
Figura 2 - Mapa do resultado da pesquisa

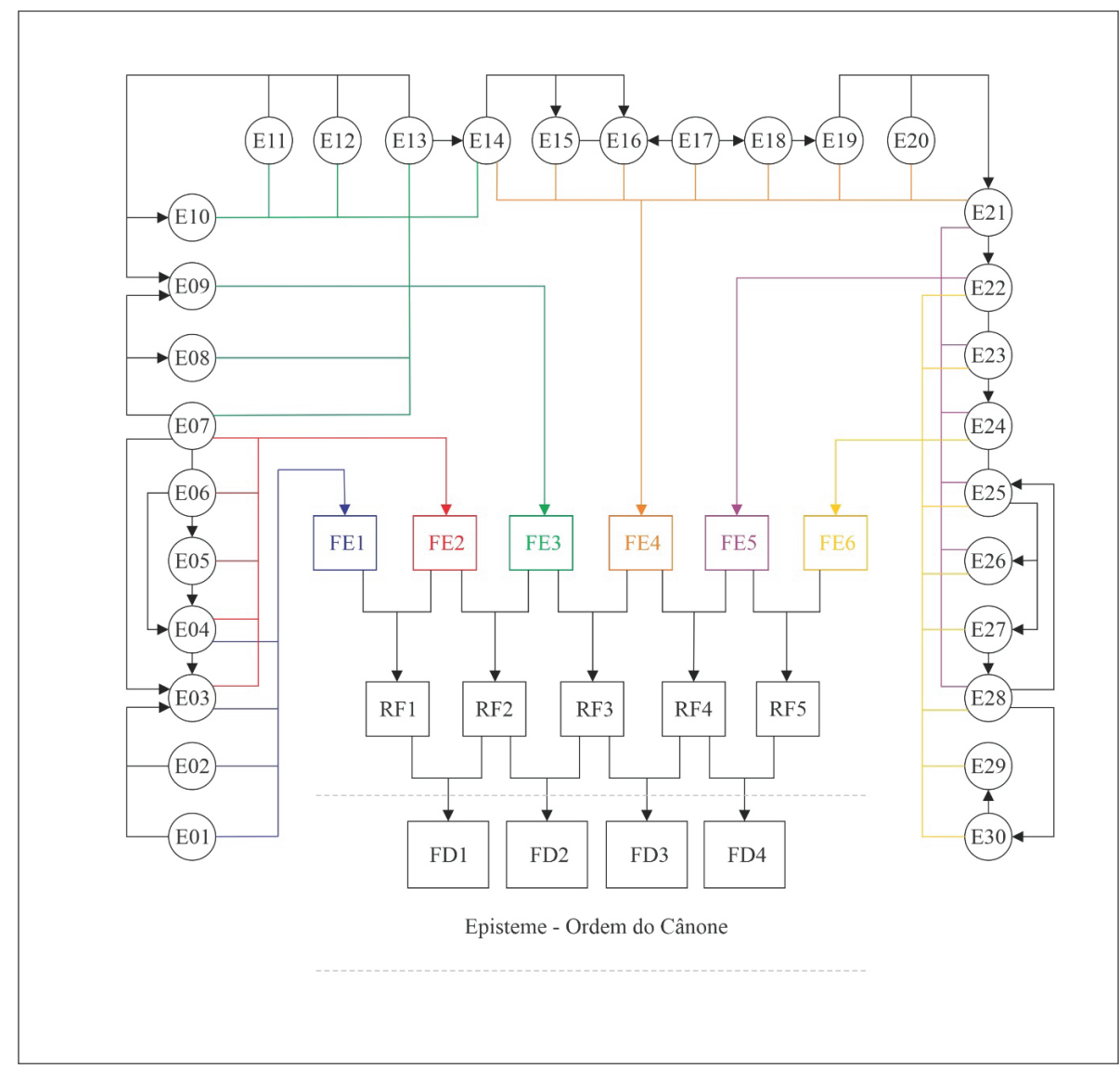

Fonte: elaboração dos autores.

com a série quando assentem sua adaptação (materialidade) televisiva enquanto forma de expressão da saga.

A função é inicialmente sustentada por enunciados correlatos que indicam que GoT é um texto mercadológico (E01) elaborado sob os critérios necessários para atender aos interesses de sua produtora (e.g., maior audiência, lucros, reconhecimento crítico, prêmios), que, por sua vez, é qualificada para realizar a adaptação (E02), a partir de expertise e prestígio que conseguiu por meio de outras de suas produções exitosas (e.g., The Sopranos). Ambos explicam (incidem sobre) GoT atrair novos fãs para ASoIaF (E03), uma vez 
que a mídia televisiva é mais popular e atrativa do que a literatura. Este entendimento (E04) também é sustentado (sofre incidência) pela concepção de que o sucesso da adaptação não depende de uma semelhança estreita a saga original (E04); que o êxito do show decorre, em parte, de como as características do meio (e.g., atuação, fotografia, direção, capacidade de entretenimento, estratégias de marketing) contribuem para isso.

Outra função enunciativa reconhece o entretenimento em GoT (FE2), quando fãs tratam da validade que a transmidiação de ASoIaF propicia aos consumidores da saga. Tendo em vista o usufruto satisfatório propiciado por assistir a série, a adaptação de ASoIaF (referencial) revela-se como exitosa para a indústria do entretenimento (campo associado). É o envolvimento (sujeito) dos fãs de ASoIaF com particulares propiciadas pela série que os leva a assentir sobre a adaptação (materialidade).

A função também está atrelada a concepção de que o êxito do show independe de uma fidelidade ao objeto cultural ao qual se inspira (E04) que, por sua vez, é reforçada (sofre incidência) por duas enunciações próximas. A primeira trata da consideração de GoT como uma das melhores séries de TV (E05) e a segunda da apreciação do programa por seus elementos técnicos e visuais (E06). A segunda se funda (incide sobre) na primeira na forma que os fãs exaltam como particularidades do segmento televisivo (e.g., efeitos de som, trilha sonora, direção, atuação) valorizam conceitos estabelecidos nos livros. Ainda, é a segunda enunciação que apresenta sincronicidade a outra que indica como a versão da saga para TV é simples e divertida (E07). A narrativa da adaptação é menos complexa (i.e., menos personagens centrais ou coadjuvantes e as respectivas relações entre) e mais adequada à uma mídia mais fluída (i.e., maior importância às cenas de ação ou fantasia) como a televisão. Entre os destaques desse divertimento, os fãs apontam uma oportunidade de leitura mais leve, mas que lhes demanda uma nova relação de consumo: assiduidade e compromisso rotineiro para, semanalmente, visitar o universo ficcional. Logo, tal enunciação incide sobre a de que GoT atrai novos fãs para o universo ficcional (E03).

A próxima função expressa como fãs tentam definir GoT como uma alternativa para ASoIaF (FE3). Existe um movimento entre o 
fandom que atesta à série a condição de possibilidade para continuar as experiências com a saga, diante, inclusive, de uma apreensão à falta dos livros que concluam sua narrativa. Neste movimento, os fãs posicionam seu envolvimento e resignação (sujeitos) que, respectivamente, revelam um conhecimento firmado tanto na sua fanidade, quanto sobre a própria saga (campos associados). Materializam, então, assentimento e conformismo (materialidades) ao tratar da adaptação de ASoIaF (referencial).

Quando fãs indicam que a simplicidade de GoT é divertida (E07), atestam (incide sobre) outras duas percepções. Por um lado, entendem que GoT proporciona uma experiencia visual de ASoIaF (E08), já que o show permite aos fãs visualizar momentos e características de personagens que, até então, eram abstratas na leitura dos livros. Por outro, que a série permite aos fãs dar continuidade à suas experiências com a saga (E09), quando em determinada fase do ano (i.e., temporada) lhes propicia um encontro semanal com o universo ficcional. Num outro tom, há a concepção de que o show proporciona novas experiências aos fãs da saga (E10), quando as diferenças entre os textos midiáticos de ASoIaF são entendidas como uma fruição inédita de seu conteúdo. Estas duas últimas enunciações podem ser explicadas (sofrem incidência) por outros três enunciados. Primeiro, na concepção de que a adaptabilidade de GoT à saga é garantida por $\mathrm{D \& D}(\mathrm{E} 11)$, quando parte do fandom repercute o cuidado dos produtores de, mesmo com limitações inerentes à mídia televisiva, seguir a lógica estabelecida nos livros. Na sequência, na enunciação que GoT é um produto que precisa tomar liberdades à ASoIaF (E12), por ser construído para outra mídia, quiçá outro público. Por fim, no medo dos fãs de que GRRM não consiga publicar a conclusão do universo ficcional (E13) que criou, visto que há um incomodo crescente acerca do hiato entre publicações dos livros, estimulado ainda mais pelo avanço da idade do autor (i.e., nascido em 1948). Tal receio, inclusive, explica (incide sobre) o entendimento de que embora a adaptabilidade de GoT à ASoIaF seja limitada, o programa é positivo (E14), por ser a única garantia de conhecer o final da trama da saga.

A função enunciativa que aceita as limitações de GoT ante ASoIaF (FE4), revela como os fãs assumem que o produto da trans- 
midiação falha em atender às expectativas daqueles que conhecem os detalhes da saga. Contudo, eles ainda consideram o show televisivo como possibilidade de entretenimento e catalisador de atividades fânicas arroladas à saga. Num movimento que emana da fanidade (campo associado) com ASoIaF, o fandom trata das diferenças narrativas (referencial) entre a mídia original e a adaptação. Assim, os fãs assumem papéis de decepção e desaprovação (sujeitos) que, respectivamente, refletem um conformismo e uma censura (materialidades) à série televisiva.

A função parte da percepção contraditória dos fãs que tanto reconhecem a qualidade televisiva da série, quanto suas falhas enquanto adaptação (E14). Esta explica (incide sobre) outros dois entendimentos: de que críticas à GoT podem melhorar sua condução (E15) e como opiniões fânicas distintas sobre a série precisam ser equilibradas (E16). Ambas atuam de forma síncrona entre si, considerando que se estabelecem em comentários aprofundados que tentam propor solução para falhas decorrentes da transmidiação da saga. Contudo, apenas a segunda é corroborada (sofre incidência) pela enunciação indica como debates sobre GoT aprimora os fãs da saga (E17), ao possibilitar expressão ou aprofundamento do conhecimento e relação com o cânone do universo ficcional. Tal enunciação, por sua vez, também incide na concórdia de a série promove uma reflexão sobre ASoIaF (E18): apesar de ser ter uma narrativa superficial e não condizente ao enredo original, a adaptação televisiva explicita detalhes que estão implícitos nos livros (e.g., sexualidade dos personagens, violência sexual, mutilação de corpos), retomando e criando discussões ou interpretações fânicas sobre. Na sequência, tal concórdia fundamenta (incide sobre) a concepção de que a complexidade narrativa de ASoIaF dificulta sua transmidiação (E19). É que a grande variedade de personagens e localidades, tramas que se aprofundam - simultaneamente, sobre o passado e futuro do universo ficcional - e toda uma riqueza de detalhes lógicos em aspectos místicos (e.g., mitologias, criaturas fantásticas, poderes sobrenaturais) são características singulares dos livros da saga e algo que é impensável para um show televisivo. Num outro tom, fãs refletem sobre a falta de enredo original a ser adaptado e como isso pode arruinar GoT (E20): apenas cinco dos 
sete (i.e., segundo a previsão do autor) livros foram publicados entre o lançamento da primeira e última temporada de GoT. Os dois últimos enunciados ajudam a explicar (incidem sobre) a enunciação de que há um efeito borboleta gerado nas decisões dos produtores da série (E21). Sobre o assunto, fãs consideram que desde o início da série, D\&D optaram por mudar detalhes da saga (i.e., morte de personagens) para conseguir mais audiência (i.e., manter a imprevisibilidade da narrativa onde nenhum personagem estava salvo). Isso se tornou um problema quanto a papeis-chave no desenrolar da trama, forçando novas mudanças narrativas que descaracterizam e afastam ainda mais GoT de ASoIaF.

Na sequência, há a função enunciativa que indica a desvalorização de mudanças operadas em GoT (FE5) quando, enquanto adaptação, deveria se apresentar de forma fidedigna à ASoIaF. São os fãs decepcionados e renegadores (sujeitos) que tratam das inconsistências de GoT e do distanciamento com ASoIaF (referenciais) a partir de concepções fânicas e críticas (campos associados). A forma como essa função se materializa é por meio da combinação entre censura e decepção com a transmidiação da saga.

A insatisfação com o show por causa de decisões dos seus produtores (E21) corrobora (incide sobre) a ideia de que os elogios à GoT são exagerados ou infundados (E22). Parte do fandom não chega a rejeitar a série, mas atesta que o decréscimo de sua qualidade (i.e., a partir da quinta temporada) operado pelas decisões narrativas de D\&D torna inviável defender o status de incredibilidade do show, algo que era comum acerca de suas primeiras temporadas. Por consequência, tal ideia é síncrona a que atesta que a popularização do show se deve ao apoio inicial dos fãs dos livros (E23): parte do fandom indica não mais ser possível defender GoT, mesmo tendo sido, enquanto conhecedores do universo antes da transmidiação, os responsáveis por, nas temporadas iniciais e fidedignas ao cânone, aumentar a ressonância do show na cultura pop. Tal responsabilidade dos leitores os leva (incide sobre) a enunciar uma exigência de fidelidade narrativa de GoT à ASoIaF (E24). Para parte do fandom, a série televisiva poderia se esforçar em se reaproximar da obra que lhe inspirou. Há, então, sincronicidade ao entendimento que a adaptação da saga é conduzida pelo e para o 
mercado (E25), quando os fãs indicam como a versão televisiva de ASoIaF prioriza formas de impressionar sua audiência, mesmo que isso signifique sacrificar a regularidade narrativa característica da saga. A orientação mercadológica do show pode explicar (incide sobre) duas outras percepções negativas da série. Por um lado, a reprovação da narrativa apresenta em GoT afasta fãs do universo ficcional (E26), quando a adaptação apresenta conteúdos ainda não mostrados nos livros (i.e., spoilers) e, principalmente, por se tratar de uma versão inferior ou superficial a estes. Por outro, o distanciamento narrativo entre as mídias prejudica o cânone (E27), já que falha em adaptar pontos chave da trama do universo ficcional como os livros fazem. Este, inclusive, também pode explicar (incide sobre) como as decisões dos produtores prejudica a saga (E28). Os fãs refletem no impacto negativo que as decisões de D\&D tiveram no show, ao ponto de torná-lo inválido e um desabono para a saga, servindo para explicar (incide sobre) a enunciação que trata da prioridade que o show deu a aspectos mercadológicos (E25).

Por fim, há uma função em tom mais crítico: o repúdio de GoT como expressão ASoIaF (FE6). Sua materialização inclui a censura, decepção e rejeição ao conteúdo do programa televisivo, emanadas de saberes da saga e críticos (campos associados), quando fãs se posicionam como renegadores (sujeito) da série para tratar do distanciamento e desrespeito à ASoIaF (referenciais) que veem em GoT.

Com exceção do primeiro enunciado da função anterior, todos os outros sete (E22-E28) se juntam dois inéditos para compor essa função. Dentre as enunciações apresentadas anteriormente, é o entendimento que decisões de D\&D podem prejudicar a saga como um todo (E28) que reverbera (incide sobre) na decepção dos fãs à liberdade que GRRM deu à GoT (E30). Ao deixar os produtores conduzirem o show sem seguir o conteúdo dos livros de linearmente, o autor permitiu não apenas que a série descumprisse seu papel de adaptação da saga, mas que tomasse a liberdade de revelar aspectos chave do universo ficcional de forma superficial ou mal construída. Essa decepção, portanto, funda (incide sobre) o desejo que GRRM deve concluir ASoIaF independente ao que foi apresentado em GoT (E29). 


\section{Formações Discursivas e suas Regras de Formação}

Conforme pode ser visto na Fig. 2, quatro foram as formações discursivas identificadas arroladas a cinco regras de formação. É que cada uma delas se funda por um par de regras de formação que, por sua vez, equivalem, a combinação duas das funções enunciativas.

A formação discursiva melhoria em ASoIaF através de GoT (FD1) considera que o show televisivo apresenta uma versão da saga com características próprias, ampliando conceitos do cânone desta. É adequado, portanto, para fins complementares à experiência dos fãs dos livros, seja por proporcionar novas formas de entretenimento, seja por expandir o alcance do universo ficcional e, consequentemente, a quantidade de membros do fandom.

Uma de suas regras atesta GoT como produto aprazível e virtuoso (RF1), quando fãs defendem a qualidade singular presente na adaptação televisiva. De forma enfática, defendem o potencial do programa de TV, seja por sua qualidade técnica, seja por apresentar particularidades à ASoIaF de forma inovadora numa fruição válida que lhes propicia uma experiência audiovisual capaz até de popularizar a saga para uma audiência de massa. A outra regra de formação considera GoT como uma adaptação de ASoIaF (RF2), pautada na assunção da série como expressão fidedigna aos livros. Nesta concepção, as diferenças narrativas entre as mídias são percebidas, mas relevadas como uma demanda natural da transmidiação que, como um todo, se apresenta de forma aderente à saga.

Tais regras se aproximam por compartilhar critérios, já que ambas representam como os fãs atestam o cânone (conceito) da saga no conteúdo apresentado em GoT. É que eles consideram o show televisivo como adequado (objeto), de modo a apoiar a adaptação num movimente que defende (estratégia) esta versão de ASoIaF. Ambas as regras partilham, portanto, da função enunciativa que reconhece a capacidade de entretenimento de GoT (FE2).

Contudo, são singulares, por um lado, quando o primor midiático (objeto) também é evocado para conceber GoT como um espetáculo (conceito) na primeira regra, o que a torna análoga à função enunciativa que evidencia o potencial de GoT (FE1). Por outro, pela forma que parte fandom também compara (estratégia) as duas versões de ASoIaF, na segunda regra, o que representa a função enunciativa que 
define o show televisivo como alternativa legitima para apresentar o universo ficcional (FE3).

A formação discursiva e os feixes que lhe compõem podem ser ilustrados pela Figura 3, quando um fã exalta como o quão incrível foi a experiência de assistir ao nono episódio da sexta temporada. A imersão é tamanha, que ele chegou a partilhar da agonia dos personagens em meio à uma batalha. E embora existam divergências entre a trama da adaptação e a do conteúdo original, a parte crítica do fandom deveria ser grata por poder assistir ao show. Tanto por não serem capazes de produzir um show superior ao conduzido por D\&D, como porque entretenimento está atrelado a algo saboroso e legal, não a análises criteriosas.

Figura 3 - Representação da Melhoria de GoT à ASolaF (FD1)

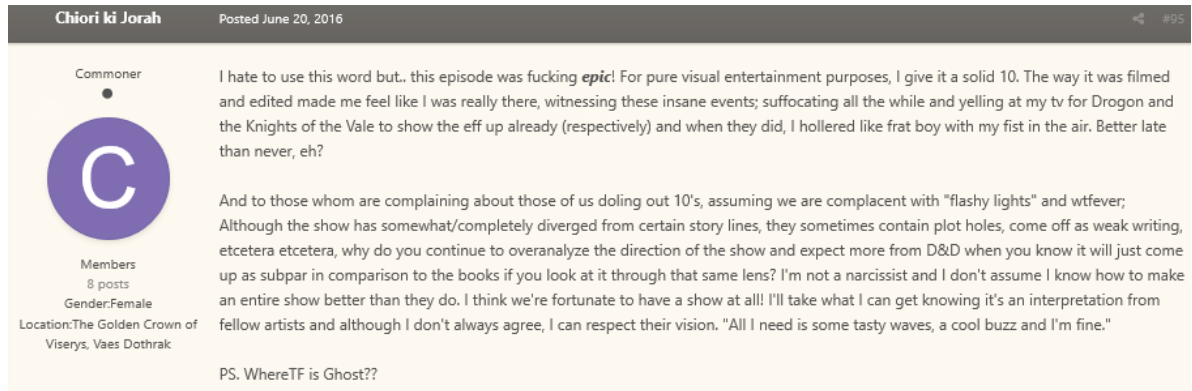

Fonte: https://asoiaf.westeros.org/index.php?/topic/141432-poll-how-would-you-rate-episode-609/page/5/\#comments [Acesso em 09 de mai. 2020].

O exemplo nos indica que programa televisivo e livros podem ser consumidos e apreciados de forma distinta, uma vez que a adaptação mantém, dentro de suas características, um alinhamento adequado ao estilo narrativo da saga. Dessa forma, os fãs podem manter e ampliar sua fruição, seja como meio de entretenimento ordinário, aprazível e virtuoso, seja como uma alternativa à imerso na experiência de leitura em outra mídia.

A próxima formação discursiva atesta as contribuições de GoT para ASoIaF (FD2). Sua substância aponta a série como uma expressão visual agradável da saga, limitada por diferentes aspectos que dificultam uma fidedignidade completa, algo que não 
compromete a possibilidade de entretenimento e continuidade de imersão à experiência. Embora a narrativa televisiva apresente certas incongruências em relação ao cânone, não se furta de entreter sua audiência. Por apresentar um conteúdo continuamente atrativo, os fãs ressoam que a adaptação se eleva ao status de expressão virtuosa do cânone, dentro de seus limites de possibilidade.

Tal formação discursiva é composta pela regra que trata da adaptabilidade do show televisivo à saga (RF2) e a que revela GoT como uma versão diferente de ASoIaF (RF3). Sobre esta, os fãs indicam que a adaptação televisiva corresponde a um nível aquém de suas expectativas. Em muito, esse entendimento esbarra em condições adversas que a distanciam a mídia televisiva da narrativa literária. Mesmo com ressalvas, refletem que o show para TV é aceitável, já que lhes proporciona entretenimento e continuidade da experiência dentro do universo ficcional.

As regras de formação têm em comum os critérios que atestam o cânone ( $\underline{\text { conceito) }}$ para comparar (estratégia) as duas versões de ASoIaF. O que representa a função enunciativa presente em ambas, a que define GoT como versão alternativa da saga (FE3). Uma das singularidades está na forma a primeira regra - adaptabilidade da série televisiva (RF2) - se funda na estratégia de defesa que os fãs executam ao atestar o show como adequado (objeto) à saga para lhe apoiar (modalidade). É, então, análoga a função enunciativa que trata GoT como possibilidade de entretenimento (FE2). A outra singularidade está na maneira que a regra que concebe a adaptação como uma versão diferente do cânone (RF3) trata das peculiaridades (objeto) observadas no show, o que gera nos fãs um desprendimento (estratégia) que, de modo indiferente, evocam uma predileção (conceito) ao conteúdo dos livros, algo que também pode ser visto na função enunciativa que aceita as limitações da transmidiação (FE4).

Destacamos o comentário de um fã sobre o sexto episódio da terceira temporada, de modo a ilustrar a convergência de feixes que sustentam a segunda formação discursiva identificada (Figura 4). Em seu comentário, o fã destaca como a transmidiação pode explicitar conteúdos que eram implícitos no primeiro. Essa expansão, inclusive, é guiada para seguir o tom do enredo original. 
Figura 4 - Representação da Contribuição de GoT à ASoIaF (FD2)

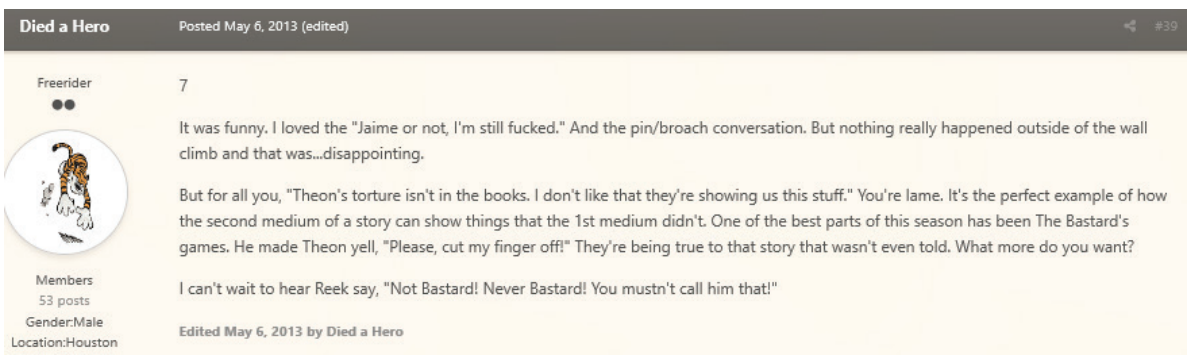

Fonte. https://asoiaf.westeros.org/index.php?/topic/86696-how-would-you-rate-episode-306/\&page=2 [Acesso em 09 de mai. 2020].

A mensagem nos revela que à despeito das diferenças entre a mídia original e a adaptada, existem benefícios no consumo de ambas. A capacidade de entretenimento de um programa televisivo expande a ressonância do texto cultural, permitindo novas rodadas de leitura deste. Já sobre as limitações impostas nesse movimento, considera que devem ser, em sua maioria, deixadas de lado em detrimento das possibilidades de fruição alcançadas. Estabelece, então, como a série televisiva, ainda que não igual aos livros, funciona como uma adaptação deles.

Em sequência, à terceira formação discursiva, percebemos que para parte do fandom GoT é inadequado à ASoIaF (FD3). Tal substância estabelece que uma adaptação entre mídias deve buscar ser o mais próxima possível aos enredos originais, respeitando o conteúdo inspirador. Isso implica que o show televisivo precisa ser conduzido sempre tendo os livros como norte. É um alinhamento narrativo entre as diferentes mídias de um mesmo objeto cultural que permite entender a segunda versão como adaptação da original.

A formação discursiva se fundamenta tanto na concepção de que o show televisivo é apenas uma alternativa para conhecer o universo ficcional estabelecido nos livros (RF3), quanto na compreensão de que GoT é uma inspiração inadequada de ASoIaF (RF4). Sobre esta, alguns fãs concebem que uma adaptação só pode ser intitulada como tal, quando apresenta, continuamente, um enredo fidedigno ao que lhe inspira. Refletem, portanto acerca das limitações inerentes à transmidiação podem limitar aspectos que devem 
ser raros e escassos, o que não ocorreu com a versão televisiva do universo criado por GRRM.

Ambas as regras tem em comum a função enunciativa trata da aceitação às limitações da série à saga literária (FE4), ao compartilhar critérios presentes quando os fãs exprimem um desprendimento (estratégia) a partir de uma predileção (conceito) do conteúdo original ao adaptado. A particularidade de uma das regras está na forma como os fãs tratam das peculiaridades (objeto) no modo indiferente, $\mathrm{o}$ que indica, analogamente, como podem atestar GoT como uma versão alternativa à ASoIaF (FE3). A da outra, está no tom desapontado (modalidade) em os fãs interagem com o objetivo de desqualificar o programa de TV, o que é similar a função enunciativa que desvaloriza as mudanças da narrativa operadas em GoT (FE5).

A Figura 5 nos parece capaz de representar a terceira formação discursiva e os feixes que lhe compõem, quando um fã opina que, cada vez mais, a série se afasta do cânone. Em sua fala sobre o sexto episódio da quinta temporada, faz coro a um movimento virtual de fãs que estão irritados com o rumo que GoT tomou. Contudo, mesmo frustrado, reconhece a permanência do interesse em assistir na mídia televisiva: quer ver adaptada a conclusão de uma trama política que une personagens carismáticas, enredo este que se apresenta de forma implícita nos livros.

\section{Figura 5 - Representação da Inaquedação de GoT à ASoIaF (FD3)}

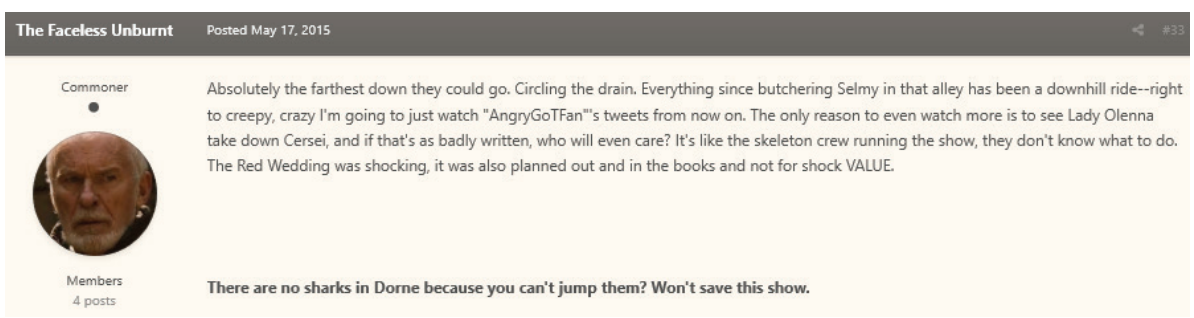

Fonte. https://asoiaf.westeros.org/index.php?/topic/129028-poll-how-would-you-rate-episode-506/page/2/\#comments [Acesso em 09 de mai. 2020].

O exemplo indica um nivelamento entre as duas formas de se relacionar com o universo ficcional. Para essa parte do fandom, 
existem alguns aspectos aproveitáveis em GoT, mas estes são esquecíveis pelas falhas narrativas de um show que se intitula adaptação do texto de GRRM. Este deveria ser o ponto principal da produção da série televisiva e não aspectos midiáticos e comerciais. É, principalmente, essa inversão de valores por parte dos produtores que incomoda os fãs que criaram expectativas de ver em outra mídia o conteúdo que leram nos livros.

A inadequação em atender ao cânone da saga (RF4) da adaptação televisiva ainda se associa à formação discursiva que revela como GoT prejudica ASoIaF (FD4). Numa alusão à decepção de fãs que esperavam ver, finalmente o enredo fantástico elaborado por GRRM, existe um repúdio à apropriação libertina operada por D\&D e cia. A fidedignidade com o cânone é requisitada não apenas para atender às expectativas dos fãs dos livros, como também, para apresentar e atrair novos fãs de forma adequada para o universo ficcional, respeitando a singularidade da obra e seus valores.

A outra regra que lhe funda estabelece GoT como perjúrio à ASoIaF (RF5) pelos fãs assimilarem que a produção da $\mathrm{HBO}$ prometera adaptar a saga literária e não se apropriar deste da forma como bem entendesse. A forma como o programa televisivo é conduzido para atender o mercado e repetindo premissas desta mídia (i.e., superficialidade de tramas) é percebido como um insulto à singularidade da saga e sua importância para o fandom. Para tanto, o distanciamento entre mídias é constatado em tons de repúdio, por poder gerar na audiência um entendimento diferente em relação aos saberes canônico, criando uma imagem equivocada da saga.

Ambas as regras tem como critérios o desapontamento (modalidade) dos fãs que desqualificam (objeto) a série para lhe criticar (estratégia), o que também pode ser traduzido pela função enunciativa que desvaloriza as mudanças que GoT trouxe à saga (FE5). Divergem quando uma também tem por conceito a predileção do conteúdo dos livros aos da adaptação televisiva, representando as limitações da transmidiação de ASoIaF (FE4). E quando a outra, num tom reprovador (modalidade), ainda busca hostilizar (estratégia) através de afrontas ( $\underline{\text { objeto }}$ ) o que é apresentado aos fãs na narrativa televisiva (conceito), equivalendo a função enunciativa que repudia GoT como expressão da saga criada por GRRM (FE6). 
Como exemplo desta formação discursiva e sua fundação, apresentamos a resposta de um fã que amplia o entendimento de outro membro do fórum sobre o sexto episódio da penúltima temporada ser um insulto ao enredo da saga. O fã retruca que a série não apenas renega os livros que lhe inspiram, como suas próprias temporadas iniciais (i.e., da primeira à quinta). Ele sente que a produção de D\&D ridiculariza uma saga que tanto ama.

\section{Figura 6 - Representação do Prejudicação de GoT à ASoIaF (FD3)}

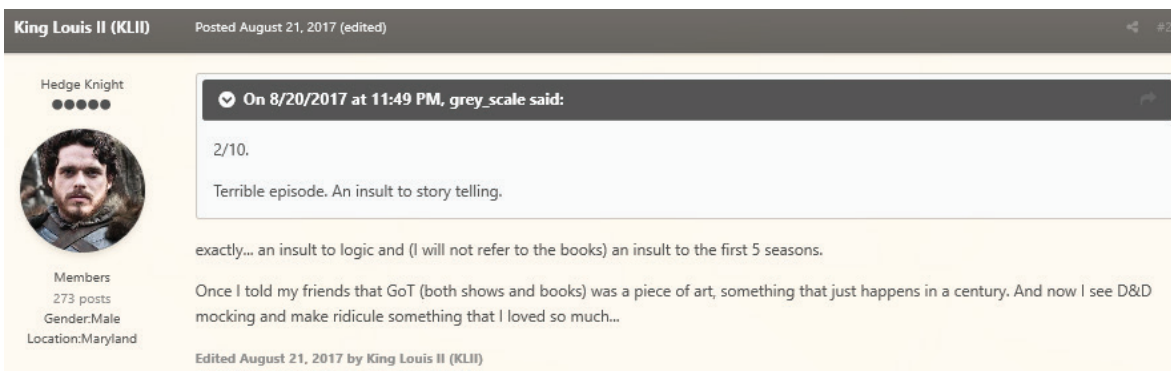

Fonte. https://asoiaf.westeros.org/index.php?/topic/147841-poll-how-would-you-rate-episode-706/ [Acesso em 09 de mai. 2020].

O comentário exprime como a série, ao se distanciar dos livros, denigre a singularidade da saga. O show televisivo não só falha em entregar para os fãs dos livros o conteúdo que esperavam visualizar, após anos de espera, mas também é uma expressão que não apresenta a aderência devida, promovendo certa letargia à uma audiência desconhecedora do valor da saga. É que um significado equivocado do universo ficcional inibe a vontade de buscar se aprofundar no conteúdo da saga e, consequentemente, a experiencia de ser fã desta. Assim, entendem a transmidiação como inadequada para que desconhece a obra original e a quebra de uma promessa com os leitores fieis desta.

\section{Episteme}

A maneira como os fãs de ASolaF se relacionam com o conteúdo que funda o universo ficcional (i.e., livros) para produzir discursos sobre GoT, revela uma gradação que representa o espaço de dispersão de saberes produzidos em meio a essa prática fânica. 
Isso porque as formações discursivas identificadas e a maneira pela qual advêm dos enunciados observados apresenta uma confluência geral do arquivo, indicando que o mesmo revela uma única episteme. No centro dessa confluência está o cânone da obra. Assim, podemos afirmar que os resultados demonstram uma episteme fundada nesse cânone.

Foucault (1996) argumenta que a organização do real é estabelecida por uma ordem do discurso, que aponta para uma organização de saberes que extrapola um exercício normativo e regulador. Essa concepção atribui ao discurso a produção de conhecimentos advindos de uma regularidade presente nas práticas discursivas. Trata-se de uma ação que produz saberes e daí possibilita o alcance de práticas não discursivas (i.e., exercícios de poder). Assim, uma ordenação de formações discursivas revela a representação das condições históricas de sua enunciabilidade e transformação.

Por consequência, existem forças e efeitos práticos que circundam os discursos, permitindo sua efetivação em práticas sociais. $\mathrm{O}$ discurso, portanto, não diz respeito ao propósito daqueles que o enunciam, sendo à manifestação de verdades que se estabelecem em meio à negociação de saberes e exercício de poderes (FOUCAULT, 1996). Essa noção de discurso funda uma concepção de linguagem entendida como representação de lutas e identidades políticas, que permite o dizer a verdade (FOUCAULT, 2016). A ordem do discurso é capaz de prover uma regularidade de constituição dos saberes mesmo diante de diferentes possibilidades de verdade (FOUCAULT, 2009).

Como os discursos de mercado se pautam em ativos imateriais, ao considerar central para os consumidores o uso de suas habilidades e conhecimentos (i.e., capacidades humanas) para expandir suas experiências de consumo (CAMPBELL; O'DRISCOLL; SAREN, 2013; JOHNSON; THOMAS; GRIER, 2017), aqueles que emergem de práticas fânicas são capazes de estabelecer verdades acerca dos produtos e os fãs que os consomem (CHEN, 2018). Neste sentido, os fãs se debruçam e incorporam para si a importância do conteúdo do texto midiático que consomem (GRAY, 2010), enunciando discursos que exaltam o cânone para aprimorar suas experiências de consumo do universo ficcional em contestações de verdades fânicas (WILLS, 2013; HILLS, 2017). 
Uma relação intensa com o cânone é fundamental à expansão do apego do fã ao produto de mídia que consome e sua participação ativa no fandom (BRENNAN, 2014; GOODMAN, 2015). Nestas interações, a discussão sobre as limitações que mídias distintas impõem ao cânone de um universo ficcional é uma prática comum e permite a identificação de lacunas narrativas, a proposição de novas perspectivas de leitura e uma gama de posições sobre o objeto cultural (GUILLORY, 1993). Por consequência, é comum que os fãs estabelecem a existência de formas para o consumo do cânone (URBANSKI, 2013). A episteme identificada na pesquisa, portanto, pode ser definida como uma Ordem do Cânone.

\section{Apontamentos Conclusivos}

A investigação revela que a produção discursiva de fãs de ASolaF sobre GoT é epistemicamente fundamentada na ordem do cânone daquele universo ficcional. As articulações discursivas evidenciadas no arquivo de pesquisa revelam que essa episteme se baliza no conteúdo original de um universo ficcional, que se sobrepõe à transmidiação executada pela indústria do entretenimento. Assim, a ordem do discurso fundamentada no cânone estabelece que este resguarda as condições determinantes do corpo de saberes que edificam a obra e legitimam seus fãs.

Ao revelar o cânone como depositário dos saberes que a produção de verdades dos fãs requer da produção transmidiática do produto de entretenimento, a presente pesquisa indica a autonomia que eles lhe atribuem em relação aos encaminhamentos dessa indústria que deve presar pela consistência narrativa de um universo ficcional como balizador transversal de suas adaptações pra diferentes plataformas. Isso sugere um processo dinâmico na significação do texto midiático (vide DENEGRI-KNOTT; TADAJEWSKI, 2017) revelando tensões entre diferentes posturas ideológicas mediadas pelo mercado (ARNOULD; THOMPSON, 2015).

Com isso, a presente investigação contribui ao campo da CCT ao respaldar o papel do consumidor como moderador da qualidade e dos significados dos produtos que lhes são ofertados. Por outro lado, a adoção da teoria foucaultiana corrobora a relevância da abordagem na pesquisa do consumidor (ver ARNOULD; THOMPSON, 
2015). De forma específica, a compreensão de práticas de produção fânica como equivalentes a práticas discursivas abre espaço para um entendimento mais amplo de que qualquer prática de consumo materialmente expressada (i.e., verbalmente, textualmente, visualmente etc.) posse ser entendida como uma produção discursiva.

A delimitação da pesquisa a um fórum de fãs que pode ser entendida simultaneamente como limite e limitação, uma vez que não busca outras esferas de produção discursiva, mas estabelece um escopo viável e representativo do fenômeno investigado. Por fim, vislumbramos que futuras pesquisas baseadas na avaliação da produção fânica em relação à transmidiação de importantes franquias da indústria do entretenimento (e.g., Star Wars, Wizarding World) poderiam contribuir para uma consolidação do entendimento do papel da produção discursivas dos fãs no delineamento desses produtos.

\section{Agradecimentos}

A Pesquisa que originou o presente trabalho foi fomentada pelo Conselho Nacional de Desenvolvimento Científico e Tecnológico (CNPq).

A Coordenação de Aperfeiçoamento de Pessoal de Nível Superior (Capes) suporta o programa de pós-graduação aos quais os autores estão vinculados.

\section{REFERÊNCIAS}

ARNOULD, E.; THOMPSON, C. J. Introduction: consumer culture theory: ten years gone (and beyond). Consumer culture theory, v. 17, n. 1, p. 1-21, 2015.

BEIGHTON, C. Groundhog day? Nietzsche, Deleuze and the eternal return of prosumption in lifelong learning. Journal of Consumer Culture, v. 17, n. 3, p. 695-712, 2016.

BOKEK-COHEN, Y. How are marketing strategies of genetic material used as a mechanism for biopolitical governmentality? Consumption Markets \& Culture, v. 19, n. 6, p. 534-554, 2016.

BOОTH, P. J. Framing alterity: Reclaiming fandom's marginality. Transformative Works and Cultures, n; 28, 2018. Disponível em https://dx.doi.org/10.3983/twc.2018.1420 Acesso em 17 de Agosto de 2020.

BOOTH, P.; KELLY, P. The changing faces of Doctor Who fandom: New fans, new technologies, old practices? Participations: Journal of Audience \& Reception Studies, v. 10, n. 1, p. 56-72, 2013. 
BRENNAN, J. The Fannish Parergon: Aca-Fandom and the Decentred Canon. Australasian Journal of Popular Culture, v. 3, n. 2, p. 217-232, 2014.

BRYCE, D.; MACLAREN, A. C.; O'GORMAN, K. D. Historicising consumption: Orientalist expectations of the Middle East. Consumption Markets \& Culture, v. 16, n. 1, p. 45-64, 2012.

BURTON, B. Game of Thrones series finale breaks HBO viewer records: More than 19 million viewers watched the final Game of Thrones episode Sunday night. CNET, 2019. Disponível em https://www.cnet.com/news/game-of-thrones-series-finale-breaks-hbo-viewer-records/ Acesso em 17 de Agosto de 2020.

CAMPBELL, N.; O'DRISCOLL, A.; SAREN, M. Reconceptualising Resources: A Critique of Service-Dominant Logic. Journal of Macromarketing, v. 33, n. 4, p. 306-21, 2013.

CHEN, Z. T. Poetic prosumption of animation, comic, game and novel in a post-socialist China: A case of a popular video-sharing social media Bilibili as heterotopia. Journal of Consumer Culture, 2018. Disponível em https://doi.org/10.1177\%2F1469540518787574 Acesso em 17 de Agosto de 2020.

CLARK, T. How 'Game of Thrones' viewership compares with TV's other most-watched shows. Business Insider, 2019. Disponível em https://www.businessinsider.com/game-of-thrones-compared-to-most-popular-tv-shows-of-2018-ratings-2019-4 Acesso em 17 de Agosto de 2020.

CANNIFORD, R.; KARABABA, E. Partly primitive: discursive constructions of the domestic surfer. Consumption Markets \& Culture, v. 16, n. 2, p. 119-144, 2012.

COVA, B.; COVA, V. On the Road to Prosumption: Marketing Discourse and the Development of Consumer Competencies. Consumption Markets \& Culture, v. 15, n. 2, p. 149-68, 2012.

DE SOUZA-LEÃO, A. L. M.; COSTA, F. N. Agenciados pelo desejo: O consumo produtivo dos potterheads. RAE-Revista de Administração de Empresas, v. 58, n. 1, 2018.

DE SOUZA-LEÃO, A. L. M.; MOURA, B. M. Temos que Pegar Todos! - Discursos Identitários sobre o Consumo de Pokémo GO no Brasil. Brazilian Journal of Marketing - BJM, v. 17, n. 6, p. 895-913, 2018.

DE SOUZA-LEÃO, A. L. M.; MOURA, B. M.; SANTANA, I. R. C.; NUNES, W. K. S.; HENRIQUE, V. M. R. Fans Make Art: Authoring and Creativity in the Production of Fanvideos. Revista de Negócios: Studing on emerging countries, v. 24, n. 4, p. 22-36, 2019.

DELEUZE, G. Foucault. São Paulo: Brasiliense, 2005.

DENEGRI-KNOTT, J.; NIXON, E.; ABRAHAM, K. Politicising the study of sustainable living practices. Consumption Markets \& Culture, v. 21, n. 6, p. 554-573, 2018.

DENEGRI-KNOTT, J.; TADAJEWSKI, M. Sanctioning value: The legal system, hyper-power and the legitimation of MP3. Marketing Theory, v. 17, n. 2, p. 219-240, 2017.

DENISON, R. Anime fandom and the liminal spaces between fan creativity and piracy. International Journal of Cultural Studies, v. 14, n. 5, p. 449-466, 2011.

DU GAY, P. Consumption and Identity at Work. London: Sage, 1996.

DUFFY, D. Situating men within local terrain: a sociological perspective on consumption practices. Consumer Culture Theory, v. 16, n. 1, p. 81-97, 2014. 
DUJARIER, M.-A. The three sociological types of consumer work. Journal of Consumer Culture, v. 16, n. 2, p. 555-571, 2014.

ELLIS, P. The Internet is Not Happy About Last Night's Explosive Game of Thrones. Mens Health, 2019. Disponível em https://www.menshealth.com/entertainment/a27451603/game-of-thrones-fan-reactions-season-8-episode-5/ Acesso em 17 de Agosto de 2020.

FOUCAULT, M. A ordem do discurso. São Paulo: Loyola, 1996.

FOUCAULT, M. A arqueologia do saber. Rio de Janeiro: Forense Universitária, 2009.

FOUCAULT, M. The history of sexuality, vol. 2: The use of pleasure. Vintage, 2012a.

FOUCAULT, M. The history of sexuality, Vol. 3: The care of the self. Vintage, 2012b.

FOUCAULT, M. As palavras e as coisas. 10ª ed. São Paulo: Martins Fontes, 2016.

FOUGÈRE, M.; SKÅLÉN, P. Extension in the Subjectifying Power of Marketing Ideology in Organizations. Journal of Macromarketing, v. 33, n. 1, p. 13-28, 2012.

FUSCHILLO, G. Beyond the Market: The Societal Influence of Fandoms. Consumer Culture Theory, p. 169-192, 2016. Disponível em https://doi.org/10.1108/S0885-211120160000018013 Acesso em 17 de Agosto de 2020.

FYRBERG YNGFALK, A. 'It's Not Us, it's Them!'-Rethinking Value Co-creation among Multiple Actors. Journal of Marketing Management, v. 29, n. 9-10, p. 1163-181, 2013.

FYRBERG-YNGFALK, A.; COVA, B.; PACE, S.; SKÅLÉN, P. Control and Power in Online Consumer Tribes: The Role of Confessions. Consumer Culture Theory, p. 325-350, 2013. Disponível em https://doi.org/10.1108/S0885-2111(2013)0000015021 Acesso em 17 de Agosto de 2020.

GALVAGNO, M. The intellectual structure of the anti-consumption and consumer resistance field. European Journal of Marketing, v. 45, n. 11/12, p. 1688-1701, 2011.

GARCIA, E.; ANTONSSON L.; MARTIN, G. R. R. The World of Ice \& Fire: The Untold History of Westeros and the Game of Thrones. New York; London: Bantam/Harper, 2014.

GIESLER, M. Conflict and Compromise: Drama in Marketplace Evolution. Journal of Consumer Research, v. 34, n. 6, p. 739-753, 2008.

GIESLER, M.; VERESIU, E. Creating the Responsible Consumer: Moralistic Governance Regimes and Consumer Subjectivity. Journal of Consumer Research, v. 41, n. 3, p. 840-57, 2014.

GODFREY, R.; LILLEY, S. Visual consumption, collective memory and the representation of war. Consumption Markets \& Culture, v. 12, n. 4, p. 275-300, 2009.

GOODMAN, L. Disappointing fans: Fandom, fictional theory and the death of the author. The Journal of Popular Culture, v. 48, n. 4, p. 662-676, 2015.

GUILLORY, J. Cultural capital: the problem of literary canon formation. Chicago: University of Chicago Press, 1993.

GURRIERI, L.; BRACE-GOVAN, J.; PREVITE, J. Neoliberalism and Managed Health Fallacies, $\mathrm{Fac}_{\text {s }}$ ades and Inadvertent Effects. Journal of Macromarketing, v. 34, n. 4, p. 532-538, 2014. 
GUSCHWAN, M. Fandom, brandom and the limits of participatory culture. Journal of Consumer Culture, v. 12, n. 1, p. 19-40, 2012.

HACKLEY, C.; HACKLEY, A. R. Advertising at the threshold: Paratextual promotion in the era of media convergence. Marketing Theory, v. 19, n. 2, p. 195-215, 2018.

HEINONEN, K.; STRANDVIK, T.; MICKELSSON, K-J.; EDVARDSSON, B.; SUNDSTRÖM, E.; ANDERSSON, P. A Customer Dominant Logic of Service. Journal of Service Management, v. 21, n. 4, p. 531-548, 2010.

HELKKULA, A.; KELLEHER, C.; PIHLSTRÖM, M. Characterizing Value as an Experience: Implications for Service Researchers and Managers. Journal of Service Research, v. 15, n. 1, p. 59-75, 2012.

HILLS, M. 'The one you watched when you were twelve': Regenerations of Doctor Who and Enduring Fandom's 'Life-Transitional Objects'. Journal of British Cinema and Television, v. 14, n. 2, p. 213-230, 2017.

JENKINS, H. Fans, Bloggers, and Gamers: Exploring Participatory Culture. New York: NYU Press, 2006.

JENKINS, H. Convergence culture: where old and new media collide. New York University Press: NY, 2008.

JENKINS, H. Textual poachers: Television fans and participatory culture. Routledge, 2015.

JENKINS, H.; FORD, S.; GREEN, J. Spreadable media: creating value and meaning in a networked culture. New York: New York University Press, 2013.

JOHNSON, G. D.; THOMAS, K. D.; GRIER, S. A. When the burger becomes halal: a critical discourse analysis of privilege and marketplace inclusion. Consumption Markets \& Culture, v. 20, n. 6, p. 497-522, 2017.

KARABABA, E.; GER, G. Early modern ottoman coffeehouse culture and the formation of the consumer subject. Journal of Consumer Research, v. 37, n. 5, p. 737-760, 2011.

KOZINETS, R. V.; HANDELMAN, J. M. Adversaries of Consumption: Consumer Movements, Activism, and Ideology. Journal of Consumer Research, v. 31, n. 3, p. 691-704, 2004.

LEÃO, A. L. M. S.; MELLO, S. C. B.; VIEIRA, R. S. G. O papel da teoria no método de pesquisa em Administração. Organizações em Contexto, v. 5, n. 10, p. 1-16, 2011.

LOWDER, J. Beyond the Wall: Exploring George R. R. Martin's A Song of Ice and Fire, from A Game of Thrones to A Dance with Dragons. Dallas: Smart Pop, 2012.

MACNEILL, K. Torrenting Game of Thrones: so wrong and yet so right. Convergence, v. 23, n. 5, p. 545-562, 2017.

MARCEL, D. Game of Thrones: os números milionários da aclamada série da HBO. Istoé Dinheiro, 2017. Disponível em https://www.istoedinheiro.com.br/noticias/mercado-digital/20150409/game-thrones-numeros-milionarios-aclamada-serie-hbo/249562 Acesso em 17 de Agosto de 2020. 
MAAS, J. 'Game of Thrones' Ties Its Own Record for Most Emmys Won by a Series in a Single Season. The Wrap, 2019. Disponível em https://www.thewrap.com/game-of-thrones-most-emmys-won-series-single-season-record-emmy-awards/. Acesso em 17 de Agosto de 2020.

MORDUE, T.; DENNIS, N. Performing jazz and the jazz constellation. Marketing Theory, v. 17, n. 2, p. 241-257, 2017.

NAVARRO, B. Creative industries and Britpop: the marketisation of culture, politics and national identity. Consumption Markets \& Culture, v. 19, n. 2, p. 228-243, 2015.

PARMENTIER, M. A.; FISCHER, E. Things fall apart: the dynamics of brand audience dissipation. Journal of Consumer Research, v. 41, n. 5, p. 1228-1251, 2015.

SARIKAKIS, K.; KRUG, C.; RODRIGUEZ-AMAT, J. R. Defining authorship in user-generated content: copyright struggles in The Game of Thrones. New Media \& Society, v. 19, n. 4, p. 542-559, 2017.

SEREGINA, A.; SCHOUTEN, J. W. Resolving identity ambiguity through transcending fandom. Consumption Markets \& Culture, v. 20, n. 2, p. 107-130, 2017.

SEREGINA, A.; WEIJO, H. A. Play at Any Cost: How Cosplayers Produce and Sustain Their Ludic Communal Consumption Experiences. Journal of Consumer Research, v. 44, n. 1, p. 139-159, 2016.

SREDL, K. C. Gendered market subjectivity: autonomy, privilege, and emotional subjectivity in normalizing post-socialist neoliberal ideology. Consumption Markets \& Culture, v; 21, n. 6, p. 532-553, 2017.

SUGIHARTATI, R. Youth fans of global popular culture: Between prosumer and free digital labourer. Journal of Consumer Culture, v. 20, n. 3, p. 305-323, 2020.

THIRY-CHERQUES, H. R. À moda de Foucault: um exame das estratégias arqueológica e genealógica de investigação. Lua Nova: Revista de Cultura e Política, n. 81, p. 215-248, 2010.

THOMPSON, C. J. Marketplace Mythology and Discourses of Power. Journal of Consumer Research, v. 31, n. 1, p. 162-80, 2004.

URBANSKI, H. The Science Fiction Reboot: Canon, Innovation and Fandom in Refashioned Franchises. Jefferson, NC: McFarlan, 2013.

VARGO, S. L.; LUSCH, R. F. Service-dominant Logic: Continuing the Evolution. Journal of the Academy of Marketing Science, v. 36, n. 1, p. 1-10, 2008.

VOASE, R. Individualism and the 'new tourism': a perspective on emulation, personal control and choice. International Journal of Consumer Studies, v. 31, n. 5, p. 541-547, 2007;

WELCH, D. Consumption and teleoaffective formations Consumer culture and commercial communications. Journal of Consumer Culture, v. 20, n. 1, p. 61-82, 2020.

WILLS, E. R. Fannish Discourse Communities and the Construction of Gender in The X-Files. Transformative Works and Cultures, v. 14. Disponível em https://doi.org/10.3983/ twc.2010.0146 Acesso em 17 de Agosto de 2020.

YNGFALK, C. Bio-politicizing consumption neo-liberal consumerism and disembodiment in the food marketplace. Consumption Markets \& Culture, v. 19, n. 3, p. 275-295, 2015. 
YNGFALK, C.; FYRBERG YNGFALK, A. Creating the Cautious Consumer. Journal of Macromarketing, v. 35, n. 4, p. 435-447, 2015.

Young, H. Race in online fantasy fandom: whiteness on Westeros.org, Continuum, v. 28, n. 5, p. 737-747, 2014.

ZAJC, M. Social media, prosumption, and dispositives: new mechanisms of the construction of subjectivity. Journal of Consumer Culture, v. 15, n. 1, p. 28-47, 2015.

Recebido em: 17-8-2020

Aprovado em: 13-11-2020

Avaliado pelo sistema double blind review.

Disponível em http://mjs.metodista.br/index.php/roc 